\title{
Body fatness, relative weight and frame size in young adults
}

\author{
By JOS A. H. BAECKE, JAN BUREMA AND PAUL DEURENBERG \\ Department of Human Nutrition, Agricultural University, De Dreijen 12, \\ 6703 BC Wageningen, The Netherlands
}

(Received 2 December 1981-Accepted 18 January 1982)

\begin{abstract}
1. Body-weight, body height, knee width, wrist width and skinfold measurements were made on males ( $n$ 139) and females ( $n$ 167) in three age-groups (20-22, 25-27 and 30-32 years). Percentage of body fat was calculated from skinfold thicknesses using regression equations according to Durnin \& Womersley (1974). Three indices of relative weight were calculated: $W / H^{2}, W / H^{p}$ and $W / W$, where $W$ is body-weight, $H$ is body height, $p$ is the exponent that made the index of relative weight independent of height and $\hat{W}$ is the weight estimated from body height and frame size.

2. The standard error of the estimate of body-weight was only reduced by $5 \%$ in males and by $13 \%$ in females when, in addition to body height, knee width was taken into account. The addition of wrist width did not improve the accuracy of estimation of body-weight in either sex. Therefore in further analyses $W$ was estimated from body height and knee width. In the present population the exponent $p$ was 1.7 in males and 1.6 in females.

3. The correlations between the percentage of body fat and the indices, $W / H^{2}, W / H^{p}$, and $W / W$, were all very similar, being approximately 0.8 in both sexes.

4. A positive relationship was observed between percentage of body fat and knee width in females, which may be explained by an artifact of measurement.

5. In conclusion it can be stated that the accuracy of estimation of percentage of body fat was not improved when the index of relative weight was adjusted for knee width or wrist width in the present population. $\mathrm{The}^{\mathrm{W}} / \mathrm{H}^{2}$ was the most preferable of the three indices which were calculated.
\end{abstract}

In epidemiological studies, several indices of relative weight have been used as indicators of obesity. Previously, in the choice of an accurate index of relative weight derived from measures of body-weight and body height, two criteria have been considered: first, the index should be relatively independent of body height and, secondly, the correlation between the index and body fatness should be as high as possible (Billewicz et al. 1962; Keys et al. 1972). In several studies the body mass index (weight/height ${ }^{2} ; \mathrm{W} / \mathrm{H}^{2}$ ) appeared to meet both criteria for adult males (Florey, 1970; Keys et al. 1972; Womersley \& Durnin, 1977; Watson et al. 1979). In other studies in which no information about body fatness was available, $\mathrm{W} / \mathrm{H}^{2}$ appeared to be almost independent of body height in males (Khosla \& Lowe, 1967; Goldbourt \& Medalie, 1974). W/ $\mathrm{H}^{2}$ has also been shown to be the most accurate index of relative weight in adult females (Womersley \& Durnin, 1977), but in other studies weight/height has been preferred (Florey, 1970; Watson et al. 1979). Another method often used to obtain an index of relative weight independent of height is to express the actual body-weight as a percentage of average weight of a reference population of the same body height and sex.

The disadvantage of the indices of relative weight mentioned previously is that they are confounded by body-build type; muscularity and skeletal robustness are not taken into account (Seltzer et al. 1970). In the weight standards established by the Metropolitan Life Insurance Company (1959), weights are categorized in terms of sex, body height and frame size, but no objective definition of frame size is given. There are several bone diameters which are related to skeletal frame size (Jackson \& Pollock, 1976; Harrison et al. 1977), but in epidemiological studies it may be easiest to measure knee width and wrist width. Furthermore, it was observed that the accuracy of estimating body-weight in young adults was not improved when, in addition to body height and knee width, other bone diameters were included in multiple regression analysis (Wijn \& Zaat, 1968). 
The purpose of the present study in young adults was first, to construct an index of relative weight adjusted for body height and frame size and, secondly, to investigate the relationship of this index and also of two weight-height indexes to body fatness derived from the sum of four skinfold thicknesses.

\section{METHODS \\ Population}

In the first part of 1980 a study was carried out in the Municipality of Ede in The Netherlands in which all inhabitants in three age-groups (19-21, 24-26 and 29-31 years as at 1 January 1980) were invited to participate (Baecke et al. 1981). Their addresses were obtained from the Civil Registration Office in Ede. All the participants from three sections of the municipality, with a distribution of sex, age and level of education comparable with the total study population, were invited again in November 1980 to participate in the present study. Complete information was obtained from 309 subjects, representing $70 \%$ of all invited subjects. Women, pregnant for 3 months or longer $(n 3)$, were excluded from further analyses.

\section{Procedure}

All subjects were invited by mail to visit a mobile research unit which was stationed in each section for $7 \mathrm{~d}$. The anthropometric measurements were made at the mobile research unit. Non-participants were visited at home in order to invite them once again to participate.

\section{Measurements}

Body-weight and body height without shoes and jacket were measured to the nearest $0.1 \mathrm{~kg}$ and $1 \mathrm{~mm}$, respectively. Knee width and wrist width were measured on both sides of the body to the nearest $1 \mathrm{~mm}$, according to Weiner \& Lourie (1969), using a GPM anthropometer. If the difference between the left and right side measurement was greater than $5 \%$, the width measurements were repeated. The sum of left and right measurements were used in further analyses. Biceps, triceps, suprailiac and subscapular skinfold thicknesses were measured, according to Durnin \& Rahaman (1967), twice on the left side of the body to the nearest $0.2 \mathrm{~mm}$ using a Holtain skinfold caliper. Body fat was calculated as a percentage of total body-weight from the average sum of the four skinfold thicknesses, using linear regression equations for 20-29-year-old males and females (Durnin \& Womersley, 1974). All measurements were made by one observer for each sex, but it was not necessary to make adjustment for observer bias, because the analyses for males and females were done separately.

Three indices of relative weight were calculated, i.e. $\mathrm{W} / \mathrm{H}^{2}, \mathrm{~W} / \mathrm{H}^{\mathrm{p}}$, and $\mathrm{W} / \hat{\mathrm{W}}$, where $\mathrm{W}$ is body-weight, $\mathrm{H}$ is body height, $\mathrm{p}$ is the exponent which made the index of relative weight independent of body height (calculated according to Benn, 1971), and $\hat{W}$ is the body-weight estimated from body height and frame size.

\section{Statistical methods}

Stepwise multiple regression analysis was done with body-weight as a dependent variable and body height, knee width, and wrist width as independent variables. Product-moment correlation-coefficients were calculated in order to study the relationship between the indices of relative weight and percentage of body fat, body height, and knee width.

\section{RESULTS}

Table 1 shows the distribution of age in the study population. The three age-groups appeared to be reasonably well represented in both sexes. Table 2 shows mean values with 
Table 1. Percentage distribution of age of the study population

\begin{tabular}{lcc}
\hline $\begin{array}{c}\text { Age } \\
\text { (years) }\end{array}$ & $\begin{array}{c}j \\
(n \text { 139) }\end{array}$ & $\begin{array}{c}q \\
(n \text { 167) }\end{array}$ \\
\hline $20-22$ & $38 \cdot 1$ & $35 \cdot 9$ \\
$25-27$ & $35 \cdot 3$ & $31 \cdot 1$ \\
$30-32$ & 26.6 & $32 \cdot 9$ \\
\hline \hline
\end{tabular}

Table 2. Mean body-weight, body height, knee width, wrist width and percentage of body fat in males and females

(Mean values with their standard errors)

\begin{tabular}{|c|c|c|c|c|}
\hline \multirow[b]{2}{*}{ Measurement } & \multicolumn{2}{|c|}{$\left(\begin{array}{c}\hat{8} \\
(399)\end{array}\right.$} & \multicolumn{2}{|c|}{$\stackrel{\stackrel{q}{1}}{(n 167)}$} \\
\hline & Mean & $\mathbf{S E}$ & Mean & $\mathrm{SE}$ \\
\hline Body-weight (kg) & 76.9 & 0.9 & 62.5 & 0.6 \\
\hline Body height $(\mathrm{cm})$ & $180 \cdot 5$ & 0.6 & $167 \cdot 3$ & 0.4 \\
\hline Knee width $(\mathrm{cm})$ & $19 \cdot 2$ & $0 \cdot 1$ & $17 \cdot 2$ & $0 \cdot 1$ \\
\hline Wrist width $(\mathrm{cm})$ & 11.5 & 0.1 & 100 & 0.0 \\
\hline Body fat $(\%)$ & $17 \cdot 0$ & 0.4 & $27 \cdot 3$ & 0.4 \\
\hline
\end{tabular}

Table 3. Regression coefficients of stepwise multiple regression analysis with body-weight ( $k g)$ as dependent variable and bone measurements $(\mathrm{cm})$ as independent variables in males and females

\begin{tabular}{|c|c|c|c|c|c|c|}
\hline \multirow{2}{*}{$\begin{array}{l}\text { Independent variables } \\
\text { Step ... }\end{array}$} & \multicolumn{3}{|c|}{$\begin{array}{c}0 \\
(n 139)\end{array}$} & \multicolumn{3}{|c|}{$\begin{array}{c}\stackrel{9}{+} \\
(n 167)\end{array}$} \\
\hline & 1 & 2 & 3 & 1 & 2 & 3 \\
\hline Intercept & $-58 \cdot 18$ & $-89 \cdot 24$ & $-85 \cdot 74$ & $-40 \cdot 39$ & -85.34 & -84.93 \\
\hline Body height & $0.75^{*}$ & $0.49^{*}$ & $0.51^{*}$ & $0.62^{*}$ & $0.33^{*}$ & $0 \cdot 34^{*}$ \\
\hline Knee width & - & $4 \cdot 01^{*}$ & $4 \cdot 42^{*}$ & - & $5 \cdot 42^{*}$ & $5.49^{*}$ \\
\hline Wrist width & - & - & $-1 \cdot 30$ & - & $\longrightarrow$ & -0.32 \\
\hline $\mathbf{R}^{2}$ & 0.29 & 0.36 & 0.37 & 0.17 & 0.38 & 0.39 \\
\hline SEE & 8.55 & $8 \cdot 11$ & $8 \cdot 11$ & $7 \cdot 53$ & $6 \cdot 52$ & $6 \cdot 54$ \\
\hline
\end{tabular}

SEE, square root of residual variance.

- $P<0.001$.

their standard errors for the anthropometric measurements. The distributions of the percentage of body fat in males and body-weight in females were slightly skewed to the right, but all other measurements had an approximately normal distribution.

The estimation of body-weight from body height, knee width and wrist width in multiple regression analysis is shown in Table 3 . It was observed that the accuracy of estimation of body-weight from body height was slightly improved in both sexes when knee width was also taken into account. The addition of wrist width in the third step did not improve the accuracy of estimation. Even when knee width was excluded, the contribution of wrist width in addition to body height was not significant in either sex. In an additional analysis, 
Table 4. Product-moment correlation-coefficients of $W / H^{2}, W / H^{p}$ and $W / \hat{W}$ with percentage of body fat, body height and knee width in males and females

\begin{tabular}{|c|c|c|c|c|}
\hline Sex & Index & $\begin{array}{l}\text { Percentage } \\
\text { of body fat }\end{array}$ & $\begin{array}{l}\text { Body } \\
\text { height }\end{array}$ & $\begin{array}{l}\text { Knee } \\
\text { width }\end{array}$ \\
\hline$\delta(n 139)$ & $\begin{array}{l}\mathbf{W} / \mathbf{H}^{2} \\
\mathbf{W} / \mathbf{H}^{1-7} \\
\mathbf{W} / \hat{\mathbf{W}}\end{array}$ & $\begin{array}{l}0.81^{* * *} \\
0.81^{* * *} \\
0.81^{* * *}\end{array}$ & $\begin{array}{r}-0.08 \\
0.03 \\
0.01\end{array}$ & $\begin{array}{l}0 \cdot 24^{* *} \\
0 \cdot 30^{* * *} \\
0 \cdot 00\end{array}$ \\
\hline q $(n 167)$ & $\begin{array}{l}\mathbf{W} / \mathbf{H}^{2} \\
\mathbf{W} / \mathbf{H}^{1 \cdot 6} \\
\mathbf{W} / \hat{\mathbf{W}}\end{array}$ & $\begin{array}{l}0 \cdot 79^{* * *} \\
0.80^{* * *} \\
0.76^{* * *}\end{array}$ & $\begin{array}{r}-0.11 \\
0.00 \\
-0.01\end{array}$ & $\begin{array}{c}0.42^{* * * *} \\
0.47^{* * *} \\
-0.02\end{array}$ \\
\hline
\end{tabular}

$\mathrm{W} / \mathrm{H}^{2}$, weight $/$ height $^{2} ; \mathrm{W} / \mathrm{H}^{\mathrm{p}}$, weight $/$ height $^{\mathrm{p}}$ ( $\mathrm{p}$ is 1.7 in males and 1.6 in females); W/W, weight $/$ predicted weight (weight is predicted from the multiple regression equation with height and knee width).

** $P<0.01$, *** $P<0.001$.

the interaction term of body height and knee width was introduced, but did not appear to be statistically significant. As the accuracy of estimation of body-weight was not improved after logarithmic transformations of all measurements, the simpler equations without transformation were used to calculate $\hat{W}$.

The relationships of $\mathrm{W} / \mathrm{H}^{2}, \mathrm{~W} / \mathrm{H}^{\mathrm{p}}$, and $\mathrm{W} / \mathrm{W}$ with percentage of body fat, body height, and knee width are shown in Table 4 . In the present study the exponent $\mathrm{p}$ in $\mathrm{W} / \mathrm{H}^{\mathrm{p}}$, which rendered an index of relative weight almost completely independent of body height, was 1.7 in males and 1.6 in females. The correlations of the percentage of body fat with the three indices were all equal in males $(0.81)$. In females, the correlations of the percentage of body fat with the three indices were similar, although the correlation with $W / \hat{W}$ was slightly lower $(0.76)$. This finding may have been due to an artifact of measurement, because the correlation between the percentage of body fat and knee width was $0.26(P<0.001)$ in females. As a consequence of the latter, the index adjusted for knee width $(W / W)$ was inevitably adjusted to some extent for body fatness. All three indices were independent of body height, but $\mathrm{W} / \mathrm{H}^{2}$ and $\mathrm{W} / \mathrm{H}^{\mathrm{p}}$ correlated with knee width in both sexes.

\section{DISCUSSION}

The densitometric method has often been considered to be the most accurate method of determining body fatness in vivo, but Womersley \& Durnin (1977) estimated that the accuracy of the densitometric method and the skinfold method in the prediction of percentage of body fat are probably of the same order of magnitude. Thus, it seems reasonable to assume that the skinfold method is an adequate reference for body fatness in the present study.

The standard error of the estimate of body-weight was only reduced by approximately $5 \%$ in males and by approximately $13 \%$ in females when, in addition to body height, knee width was taken into account. The regression coefficients of knee width suggested that knee width had a great influence on body-weight in both sexes. However, it should be noted that the regression coefficient of body height decreased considerably, when knee width was added as an independent variable, because of a relationship between body height and knee width. Wrist width did not improve the accuracy of estimation of body-weight. Similarly, it was shown in a study in young adults that the additional contribution of shoulder, chest and pelvic widths was also small (Wijn \& Zaat, 1968). Explanations for these findings may well be: first, that only a small proportion of body-weight consists of bone tissue (approximately 14\%; Passmore \& Robson, 1973); secondly, that bone mass can be 
predicted mainly from body height; and thirdly, that there is a weak relationship between bone diameters and muscle mass (Harrison et al. 1977). Brozek (1956) suggested that the lateral size of the bony frame of the trunk is closely related to the size of the skeletal musculature and viscera. Thus, it may be implied that the bone diameters of the trunk are more important in the prediction of body-weight than diameters of limb bones, but this is not in accordance with the findings of Wijn \& Zaat (1968).

The correlation of the percentage of body fat with $W / \hat{W}$ was not higher than the correlation of the percentage of body fat with $\mathrm{W} / \mathrm{H}^{2}$, and with $\mathrm{W} / \mathrm{H}^{\mathrm{p}}$. This finding is in agreement with the small improvement in the accuracy of estimation of body-weight from knee width. In females, the correlation of the percentage of body fat with $W / \hat{W}$ was even smaller than the correlation of the percentage of body fat with $\mathrm{W} / \mathrm{H}^{2}$, and with $\mathrm{W} / \mathrm{H}^{\mathrm{p}}$. This finding may well be the result of an artifact of measurement, because some subcutaneous fat may be unavoidably included in the anthropometric measurement of knee width (Harrison et al. 1977). The relationship between the percentage of body fat and knee width was only significant in females. Keys et al. (1967) observed a positive relationship between the laterality-linearity index (sum of the bi-acromial and bi-cristal diameter:total body height) and skinfold thickness in adult males, which was not considered to be the result of an artifact of measurement. The suggested artifact may only occur in the measurement of knee width. This is supported by another study in adults, in which it was shown by factor analysis, that the anthropometric measurement of knee width was related to fat measurements, but this relationship was not observed for the bi-acromial and bi-cristal diameter measurements (Harrison et al. 1977).

No difference was found between the correlation of the percentage of body fat with $\mathrm{W} / \mathrm{H}^{2}$, and with $\mathrm{W} / \mathrm{H}^{\mathrm{p}}$ in males, and the difference in females was negligible. This can be explained by the fact that $\mathrm{W} / \mathrm{H}^{2}$ is almost independent of body height in this population. The correlation of $\mathrm{W} / \mathrm{H}^{2}$ with the percentage of body fat was of the same order of magnitude as was found in adult males by Keys et al. (1972).

In conclusion, it can be stated that the relationship between the percentage of body fat and the index of relative weight was not improved after the index had been adjusted, not only for body height, but also for knee width or wrist width. Adjustment of the index of relative weight for other bone diameters is also unlikely to improve the accuracy of prediction of body fatness, because of the small improvement in the accuracy of estimation of body-weight when, in addition to body height and knee width, other bone diameters are taken into account (Wijn \& Zaat, 1968). This would have the practical consequence that, in general, adjustment of body-weight for skeletal frame size does not improve the accuracy of prediction of body fatness. The $\mathrm{W} / \mathrm{H}^{2}$ often referred to as the body mass index, is the most preferable of the three indices which were calculated. This index appeared to be the most accurate index of relative weight for adults in several studies, and hence has been used regularly, with the additional advantage of making comparisons between studies easier.

The authors wish to thank the Praeventiefonds in The Netherlands for the financial support for this study; the Local Government Office and the Civil Registration Office in Ede for assistance in the preparation of the study population; and all the people who participated in the study. They would also like to thank C. Baerends-Bos, W. Knuiman-Hijl, E. Oosterhaven-Rappard, W. van der Wiel-Wetzels, B. Scholte and H. West for technical assistance with the study.

Baecke, J. A. H., Burema, J., Wiel-Wetzels, W. A. M. van der (1981), Prevalentie van overgewicht bij jonge volwassenen in Ede. Wageningen: Department of Human Nutrition, Agricultural University.

Benn, R. T. (1971). Br. J.prev. soc. Med. 25, 42. 
Billewicz, W. Z., Kemsley, W. F. F. \& Thomson, A. M. (1962). Br. J. prev. soc. Med. 16, 183.

Brozek, J. (1956). Science, N.Y. 124, 685.

Durnin, J. V. G. A. \& Rahaman, M. M. (1967). Br. J. Nutr. 21, 681.

Durnin, J. V. G. A. \& Womersley, J. (1974). Br. J. Nutr. 32, 77.

Florey, C. du V. (1970). J. Chron. Dis. 23, 93.

Goldbourt, U. \& Medalie, J. H. (1974). Br. J. prev. soc. Med. 28, 116.

Harrison, G. A., Weiner, J. S., Tanner, J. M. \& Barnicot, N. A. (1977). Human Biology, 2nd ed. Oxford: University Press.

Jackson, A. S. \& Pollock, M. L. (1976). Med. Science Sports 8, 196.

Keys, A., Aravanis, C., Blackburn, H. W., Buchem, F. S. P. van, Buzina, R., Djordjević, B. S., Dontas, A. S., Fidanza, F., Karvonen, M. J., Kimura, N., Lekos, D., Monti, M., Puddu, V. \& Taylor, H. L. (1967). Acta Med. Scand. Suppl. 460, 289.

Keys, A., Fidanza, F., Karvonen, M. J., Kimura, N. \& Taylor, H. L. (1972). J. Chron. Dis. $25,329$.

Khosla, T. \& Lowe, C. R. (1967). Br. J. prev. soc. Med. 21, 122.

Metropolitan Life Insurance Company (1959). Stat. Bull. 40, 1.

Passmore, R. \& Robson, J. S. (1973). A Companion to Medical Studies, vol. 1, 2nd ed. Oxford: Blackwell Scientific Publications.

Seltzer, C. C., Stoudt, H. W. Jr., Bell, B. \& Mayer, J. (1970), Am. J. Epidemiol. 92, 339.

Watson, P. E., Watson, I. D. \& Batt, R. D. (1979). Am. J. clin. Nutr. 32, 736.

Weiner, J. S. \& Lourie, J. A. (1969). Human Biology. A Guide to Field Methods, 1st ed. Oxford: Blackwell Scientific Publications.

Wijn, J. F. de \& Zaat, J. C. A. (1968). Voeding 29, 208.

Womersley, J. \& Durnin, J. V. G. A. (1977). Br. J. Nutr. 38, 271. 